\title{
LUTA DO POVO INGARIKÓ POR RECONHECIMENTO E REDISTRIBUIÇÃO NO TERRITÓRIO SOBREPOSTO AO PARQUE NACIONAL DO MONTE RORAIMA, RR
}

\author{
Oseias Cordeiro Sartori \\ Universidade Federal do Amazonas - UFAM \\ Doutorando no Centro de Ciências do Ambiente, Manaus, AM, Brasil \\ oseias.sartori@gmail.com \\ Henrique dos Santos Pereira \\ Universidade Federal do Amazonas - UFAM \\ Professor Titular, Manaus, AM, Brasil \\ pereira@ufam.edu.br
}

\begin{abstract}
RESUMO
Este artigo se concentra na reação do povo Ingarikó à invisibilização praticada pelo poder público por ocasião da criação do Parque Nacional do Monte Roraima, no ano de 1989. Sua construção se apoiou no cruzamento de informações oriundas de levantamento bibliográfico e análise documental, assim como em visitas de campo voltadas à confirmação das informações acessadas. Os resultados indicaram que os indígenas consideraram sua situação de invisibilidade perante o poder público como a principal causa da criação da unidade de conservação. Como reação, iniciaram uma luta por reconhecimento e redistribuição pautada em estratégias de representação, negociação e resistência. Conclui-se que a organização de eventos denominados assembleias gerais permitiu aos autóctones a exposição de suas demandas e a oportunização de diálogos com o órgão ambiental responsável pelo parque nacional. Ao mesmo tempo, a resistência Ingarikó passou a condicionar a gestão da área sobreposta à visibilidade da territorialidade indígena e suas expectativas para o futuro.
\end{abstract}

Palavras-chave: Unidade de conservação. Território indígena. Representação. Negociação. Resistência.

\section{THE INGARIKÓ PEOPLE STRUGGLE FOR RECOGNITION AND REDISTRIBUTION IN THE TERRITORY OVERLAPPING TO THE MONTE RORAIMA NATIONAL PARK, RR}

\begin{abstract}
This article focuses on the reaction of the Ingarikó people to the invisibility practiced by the Government when the Monte Roraima National Park was created, in 1989. Its construction held at the intersection of information from bibliographical and documental analysis as well as field visits focused on confirmation of information accessed. The results indicated that the Indians consider your situation of invisibility to the Government as the main cause of the creation of the protected area. As a reaction, the Indians to begin a struggle for recognition and redistribution based on strategies of representation, negotiation and resistance. It is concluded that organizing events such as general assemblies, the indigenous people were able to present their demands and deal with the environmental agency responsible for the National Park. At the same time, the Ingarikó resistance began to condition the management of the overlapped area to the visibility of indigenous territoriality and their expectations for the future.
\end{abstract}

Keywords: Protected area. Indigenous territory. Representation. Negotiation.

Resistance. 


\section{INTRODUÇÃO}

A área estudada corresponde à sobreposição entre o Parque Nacional do Monte Roraima (PNMR) e o território do povo Ingarikó. O PNMR foi criado pelo Decreto no 97.887, de 28 de junho de 1989. Segundo Brasil (1989), seus 116 mil hectares estão localizados no município de Uiramutã, a nordeste de Roraima. Para Lauriola (2011) e Brasil (2017), a incidência do PNMR sobre o território dos Ingarikó afeta uma população que em 2016 contava com 1576 pessoas distribuídas em onze comunidades.

Para facilitar a criação do PNMR, o poder público utilizou a estratégia de invisibilização do povo Ingarikó. Embora a estratégia tenha atendido os interesses estatais durante os trâmites relativos à gênese do parque nacional, conforme defende Silveira (2010), não conseguiu evitar a resistência indígena no processo de gestão da unidade de conservação.

Sem conhecer as reais intenções do poder público, os autóctones apontaram sua situação de invisibilidade perante o governo como uma das causas do estabelecimento da sobreposição em seu território. Essa constatação motivou o empreendimento de uma luta por reconhecimento e redistribuição pautada em estratégias de representação, negociação e resistência. A análise dessa luta indígena corresponde ao objetivo desse estudo.

A discussão desse tema se justifica pela dificuldade encontrada na gestão das unidades de conservação sobrepostas a territórios indígenas, situação considerada problemática por autores como Arruda (1999), Ricardo e Macedo (2004), Abi-Eçab (2008), Rodrigues e Ferreira (2013) e Silva e Silva (2014). Grande parte dos desafios são impostos pela invisibilidade das territorialidades indígenas. A recusa do poder público em reconhecer as ações de ocupação, uso, defesa e identificação com o espaço vivido impede que os processos de gestão executados pelos autóctones sejam considerados parte do contexto da administração das áreas superpostas.

Por outro lado, o avanço da consciência indígena sobre os processos de invisibilização impele um número cada vez maior de sociedades autóctones a empreenderem lutas por reconhecimento e redistribuição. Se os planos de gestão não considerarem as territorialidades indígenas, se tornarão inviáveis a médio e longo prazo pelo surgimento de estratégias de gestão concorrentes na mesma unidade espacial.

No caso analisado, as dificuldades de gestão começaram a ser estabelecidas pela atitude do governo de invisibilizar a territorialidade do povo Ingarikó. Esse problema impediu as necessárias aproximações com os indígenas no período de criação do PNMR. Assim, as questões urgentes daquele momento foram transferidas para os dias atuais. Além de tornar o seu enfrentamento mais difícil por se tratar de uma situação imposta, os diálogos sobre a conciliação entre a proteção integral e o usufruto indígena ocupam o tempo e os esforços que poderiam estar sendo direcionados às estratégias de conservação da biodiversidade.

\section{PROCEDIMENTOS METODOLÓGICOS}

As discussões resultam do cruzamento de informações oriundas de levantamento bibliográfico e análise documental. Os documentos acessados foram o plano de manejo do PNMR, conforme Brasil (2000), o documento denominado SOS Monte Roraima, disposto em Brasil (2004), o Plano de Administração Conjunta, Segundo Brasil (2008), assim como relatórios das assembleias gerais do povo Ingarikó. Para melhor entendimento do território Ingarikó, foram realizadas observações de campo nas onze comunidades por meio de seis expedições com duração de quinze dias entre os meses de maio de 2017 e fevereiro de 2018. Para complementar as observações, foram realizadas visitas às casas de apoio utilizadas pelo povo Ingarikó na cidade de Boa Vista/RR no mesmo período mencionado.

Segundo Brasil (2000), a área sobreposta analisada se encontra entre as coordenadas geográficas $04^{\circ} 48^{\prime}$ a $05^{\circ} 16^{\prime}$ Latitude Norte e $60^{\circ} 05^{\prime} 60^{\circ} 44^{\prime}$ Longitude Oeste. Todo o PNMR se superpõe ao território do povo Ingarikó, situado ao norte da Terra Indígena Raposa Serra do Sol, município de Uiramutã, Roraima. Os limites da área sobreposta coincidem com a linha de fronteira internacional, fazendo fronteira com a Venezuela na face Oeste e com a Guiana ao Norte (Figura 1). 
A área compõe a chamada região Circum-Roraima, definida por Santilli (2001) e Fiorotti (2017) como o entorno do Monte Roraima. Segundo Frank (2008), a ocupação indígena na área é milenar. Sucedendo seus antepassados, o território do povo Ingarikó guarda toda a história desses indígenas. Segundo a Fundação Ecoamazônia (2018), entre os anos de 1943 e 1995 a população Ingarikó sofreu expressivas oscilações. Em períodos mais recentes, Brasil (2017) tem atestado um crescimento mais constante que propiciou o alcance de uma população de 1.576 pessoas no ano de 2016.

Figura 1 - Mapa da área de estudo.

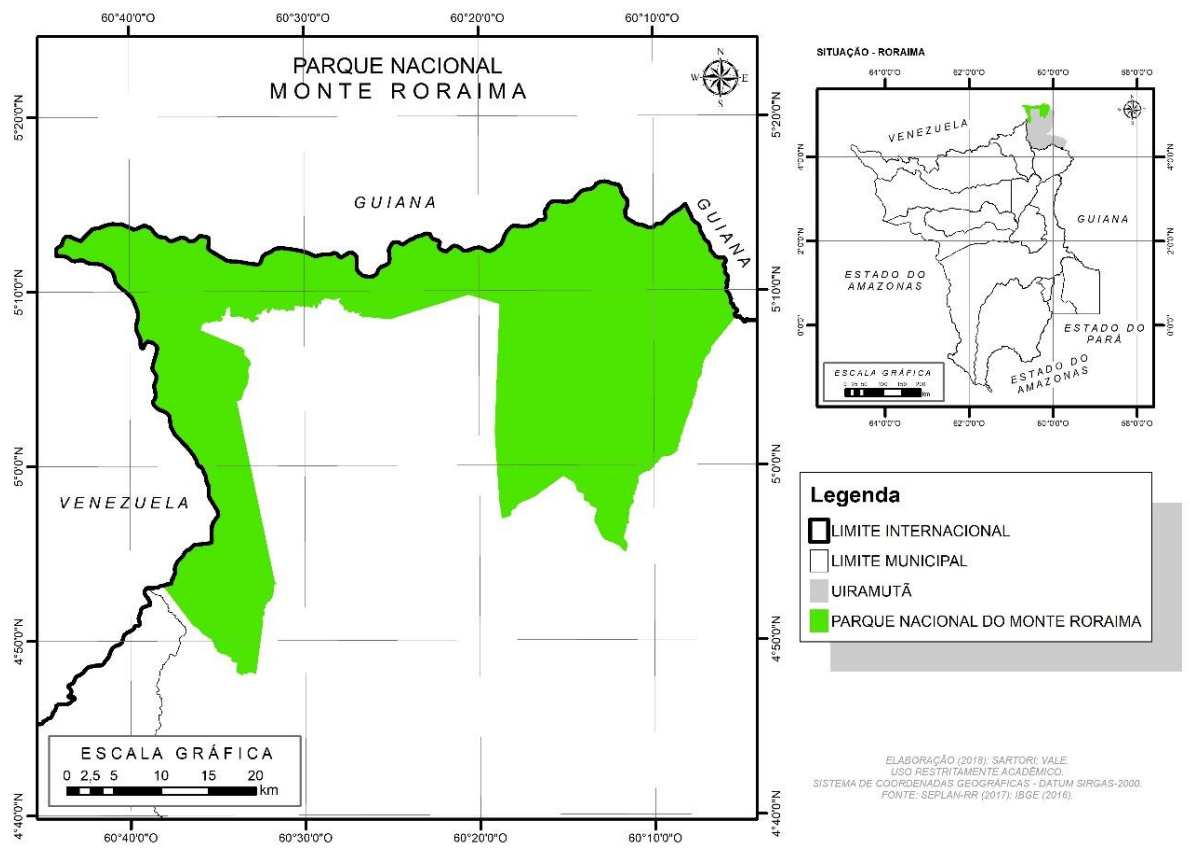

Fonte - Roraima (2018). Elaboração de Fernando Bruno Pinheiro Vale (2018)

\section{RESULTADOS}

Ao tomarem conhecimento da existência de um parque nacional em seu território, os Ingarikó consideraram a sua invisibilidade perante o poder público como a principal razão para a iniciativa do poder público. Como reação, iniciaram uma luta por reconhecimento e redistribuição pautada em estratégias de representação simbólica, negociações com o órgão ambiental e resistência às interferências externas ao seu modo de vida.

A opção pela própria representação, antes delegada a outros povos e organizações indígenas, implicou na organização de eventos anuais organizados no próprio território. A participação de diversas instituições públicas propiciou a exposição de suas demandas de forma conjunta com demonstrações da sua cultura. Os mesmos eventos foram utilizados como canal de negociação com o órgão ambiental durante a elaboração do plano de administração conjunta, determinado pelo Decreto de 15 de abril de 2005.

Quando o estatuto da gestão tripartite envolvendo os órgãos ambiental e indigenista e o povo Ingarikó foi desfeito pelo Supremo Tribunal Federal (STF), os indígenas avançaram na estratégia de resistência. Ao saberem da impossibilidade do órgão ambiental realizar a administração de forma unilateral, seguiram executando a gestão territorial da área sobreposta conforme os pressupostos da sua própria territorialidade.

Após alguns anos o governo reconheceu a dificuldade de administrar as unidades de conservação sobrepostas sem o apoio dos autóctones e instituiu normas capazes de reinstaurar o processo de negociação entre os indígenas e o poder público. Assim, a 
resistência indígena passou a condicionar a gestão da área sobreposta à visibilidade da sua territorialidade e suas expectativas para o futuro.

\section{A DESCOBERTA DE UM PARQUE NACIONAL NO TERRITÓRIO INDÍGENA}

Quando três líderes do povo Ingarikó foram convidados a participar da oficina de elaboração do plano de manejo do PNMR, não imaginavam as relações existentes entre essa área protegida e o seu território. Durante o evento realizado no primeiro trimestre do ano 2000 , os indígenas tomaram conhecimento do Decreto o 97.887, de 28 de junho de 1989, que criara uma unidade de conservação de proteção integral em seu espaço vivido. Para aqueles autóctones, a notícia chegava com mais de uma década de atraso.

Cautelosos, continuaram participando da oficina, buscando reunir mais informações sobre as implicações de um parque nacional em seu espaço vivido. Durante o evento, ouviram expressões como preservação in situ, zona intangível, área fonte, zona de amortecimento, características geológicas e geomorfológicas. Ao término das atividades, os indígenas que haviam iniciado os contatos mais frequentes com a sociedade envolvente em pouco mais de uma década já sabiam sobre a existência de algo, envolvendo uma série de nomes estranhos, criado pelo governo em seu território.

Essas novidades foram compartilhadas com os demais integrantes do povo Ingarikó, suscitando muitos questionamentos. Levaram algumas perguntas ao povo Macuxi, mas seus vizinhos não puderam responder. Em julho do mesmo ano, aproveitando a presença da Fundação Nacional do Índio (FUNAI) na Assembleia Regional dos Tuxauas da Região das Serras, lideranças Ingarikó e Macuxi abordaram o caso do PNMR. Segundo Lauriola (2011), os indígenas demonstraram preocupação com essa instituição nova e desconhecida.

Para Mlynarz (2006), a carência de entendimento sobre o parque nacional justificou a realização de uma missão de esclarecimentos e registros dos posicionamentos do povo Ingarikó. A ação empreendida pela FUNAl entre agosto e setembro de 2000 foi liderada por Martinho Alves de Andrade Júnior e Vincenzo M. Lauriola. Segundo Lauriola (2011), após discorrerem sobre o conteúdo do plano de manejo do PNMR, puderam registrar 0 posicionamento contrário dos Ingarikó à existência do parque nacional.

Ao procurarem as causas da criação da política pública preservacionista em seu território, os indígenas pensaram na invisibilidade da territorialidade Ingarikó perante o poder público. Também concluíram que a reação à atitude injusta e desrespeitosa do governo deveria envolver uma luta indígena por reconhecimento e redistribuição.

\section{LUTA POR RECONHECIMENTO E REDISTRIBUIÇÃO}

Há muitos anos o povo Ingarikó havia experenciado um tipo de invisibilidade considerada por Wiesner e Devargas (2013) uma política cotidiana para uma vida com dignidade. O desejo de se afastar dos conflitos provocados pelos contatos com os europeus conduzira a uma invisibilidade desejada. Naquele período, os indígenas utilizaram a floresta como camuflagem para se esconderem dos inimigos.

A partir do ano de 1989 surgiu uma invisibilidade de novo tipo, caraterizada pela recusa do Estado em reconhecer a presença dos indígenas na área do PNMR. Para Honneth e Margalit (2015), esse tipo de invisibilidade possui um sentido real e outro figurado, marcado pela negação em ver aquilo que foi nitidamente percebido. Simim (2015) defende a existência de dois momentos nesse processo de invisibilidade. Num primeiro plano, existe a completa percepção da pessoa ou grupo. Depois ocorre a decisão de não ver.

Essa atitude pressupõe uma intencionalidade, vista por Tomás (2008) como a estrutura essencial da consciência que visa dar significado ao que o olho percebe. Sendo a consciência a doadora de sentido, o ato de ver se transforma numa operação ou mesmo numa criação. Nesse sentido, a percepção se pauta por motivações, vendo ou se recusando a ver de forma intencional. Em um mundo marcado pela atribuição de diferentes níveis de importância ao que se observa, a experiência subjetiva se torna a única responsável por conferir objetividade à realidade. 
Assim, na criação do PNMR a subjetividade do poder público passou a conduzir a sua própria objetividade, revelando uma atitude consciente e intencional de não ver o povo Ingarikó. Esse comportamento se ajustou às ideias de Cittadino (2005) sobre o invisibilizador se apoiar em sua condição de poder dominante para praticar a invisibilização. Em suas ações relativas ao parque nacional, o Estado lançou sobre os indígenas o que Merigueti (2017) ilustra como um véu imaginário, tornando os autóctones invisíveis aos olhos governamentais.

A ação de não ver um povo fisicamente visível demandou a recusa em emitir os sinais de reconhecimento. Nesse sentido, as visitas de representantes do poder público ao território Ingarikó desde o ano de 1934, conforme Cruz (2005), além da farta literatura e a grande quantidade de documentos acumulados desde o período colonial, atestadas por Farage e Santilli (2018), precisaram ser ignoradas.

Diante da intenção de não ver o povo Ingarikó, o Estado se recusou a emitir os sinais de reconhecimento. Assim, decidiu não consultar os indígenas e não considerar os diversos usos indígenas no momento de definir a categoria de manejo mais apropriada. Ao configurar uma atitude de invisibilização, a ação estatal se enquadrou naquilo que Carleheden et al (2012) e Honneth e Margalit (2015) percebem como um flagrante desrespeito.

A falta dos sinais de reconhecimento levou o povo Ingarikó a acreditar que era invisível aos olhos do Estado. Segundo Buril (2017), a crença na própria invisibilidade decorre da falta de ações e reações daquele que invisibiliza. Para o autor, a parte vitimada não consegue acreditar na sua visibilidade quando as atitudes do invisibilizador atestam que a percepção não ocorreu.

Mesmo acreditando na própria invisibilidade, os indígenas puderam classificar a atitude do Estado como injusta e desrespeitosa. Para Carvalho (2015) e Moraes (2006), a percepção da injustiça e do desrespeito só se torna possível pela existência de uma estrutura moral capaz de permitir a avaliação da ausência de reconhecimento como uma valoração negativa atribuída a um indivíduo ou grupo.

A presença dessa estrutura, ou reivindicação moral, como preferem Deranti e Renault (2007), pressupõe a existência de autorreconhecimento. Segundo Pinto (2011), o autorreconhecimento se caracteriza pela consciência do desrespeito, correspondendo à condição fundamental para estimular e justificar uma luta por reconhecimento. No caso dos Ingarikó, o autorreconhecimento já era experimentado na esfera do amor, a forma mais elementar de luta por reconhecimento.

Para Honneth (2003), o reconhecimento da mãe como uma pessoa independente costuma ocorrer logo após a término da fase de simbiose, na qual a criança percebe que ela e a mãe não formam um único ser. Para Araújo e Resende (2015), a partir desse momento a criança inicia uma luta pelo reconhecimento da mãe e dos demais integrantes da família, onde o amor se torna a principal demonstração. As manifestações de reconhecimento nessa esfera ajudam a criança a desenvolver a autoconfiança.

Honneth (2003) também ressalta que uma luta por reconhecimento só pode ser caracterizada como social quando seus objetivos se deixam generalizar para além do horizonte das intenções individuais, chegando ao ponto de se transformar na base de um movimento coletivo. Nesse caso, o amor, como forma mais elementar de reconhecimento, não consegue ultrapassar o círculo traçado pela relação primária da família.

Mesmo restrita à esfera individual, as experiências no seio familiar indígena contribuíram para dotar os Ingarikó de uma estrutura moral necessária à identificação e efetivação de uma luta coletiva por direitos, considerada por Honneth (2003) como a segunda forma de reconhecimento. A partir dessa segunda esfera, a luta por reconhecimento assume um caráter coletivo.

Para Schmidt e Peterson (2009), Hirata (2011), Zurn (2015) e Mousquer (2015), questões de reconhecimento estão muito associadas a movimentos sociais. A busca por justiça, representada pela luta por reconhecimento, converge para a reafirmação da identidade de grupo. Por sua vez, a reafirmação da identidade étnica fornece um impulso para as mobilizações caracterizadas por uma luta imediatamente coletiva. 
Na perspectiva de Silva (2007), a atitude do Estado de não reconhecer os direitos dos povos indígenas caracteriza uma invisibilidade jurídica. Para Merigueti (2017), esse tipo de invisibilidade ocorre quando os direitos e garantias positivados nos textos dos instrumentos jurídico-normativos não se realizam, pois não alcançam aqueles que realmente necessitam. Nesses casos, a mobilização dos invisíveis pode ser considerada uma consequência quase inevitável.

Honneth (2003) aborda uma terceira forma de reconhecimento, caracterizada pela estima social. Numa situação de grupo, o sinal de reconhecimento dado pelo Estado corresponde ao poder de dispor de determinados bens. Assim, a estima social do povo Ingarikó estaria atrelada à possibilidade de usufruir de todos bens naturais de seu território, conforme as determinações da Constituição Federal.

Essa terceira forma de reconhecimento se relaciona com a redistribuição quando trata daquilo que Abreu (2011) chama de demandas de acesso por bens escassos ou naturais. Talvez por isso Luquiari (2018) perceba um entrelaçamento entre o reconhecimento e a redistribuição nas lutas dos povos indígenas. Embora os esforços por reconhecimento se concentrem na visibilização da cultura, também implicam no livre acesso à totalidade do seu território. A demanda por redistribuição surge quando diversos projetos, incluindo políticas públicas como as unidades de conservação, limitam o acesso aos componentes da biosfera. Para Fraser (2007), essas injustiças são ocasionadas pelas invisibilidades cultural e econômica, a primeira percebida como simbólica e a segunda como material.

Baseando-se nas perspectivas de Cyfer e Neves (2011), torna-se possível afirmar que a luta por reconhecimento nas esferas do amor, direito e estima, visando o alcance de autoconfiança, autorrespeito e autoestima, converge para a autorrealização. As ideias de Pereira (2013) sobre o reconhecimento como uma necessidade vital humana se aplicam ao povo Ingarikó, para quem a autorrealização também constitui um fator determinante para o bem-estar coletivo.

Ao empreender uma luta por reconhecimento associada com redistribuição, o povo Ingarikó recorreu a estratégias de representação, negociação e resistência. Sobre a primeira estratégia, Abreu (2011) a percebe como uma demanda por voz inserida numa concepção propriamente política de justiça. Nesse processo, os envolvidos costumam buscar mecanismos capazes de conferir maior visibilidade às suas demandas.

\section{REPRESENTAÇÃo DO POVO INGARIKó}

Conforme a perspectiva de Abreu (2011), o principal papel da representação consiste no estabelecimento de canais de manifestação das demandas não abrigadas nas estruturas institucionais tradicionais. Para Araújo e Biroli (2011), há três formas de representação: descritiva, de interesses e simbólica. A primeira envolve o compartilhamento de algumas características entre os representantes e o grupo representado. A segunda ocorre quando os representantes assumem a condição de agentes de defesa dos interesses dos representados, mesmo sem compartilhar qualquer característica do grupo. Na terceira, os representantes simbolizam completamente a identidade do grupo.

Para Ingaricó (2012), antes de tomarem conhecimento da existência do PNMR, o povo Ingarikó costumava ser representado por outros povos e organizações indígenas, tais como o Conselho Indígena de Roraima (CIR). Tratava-se de representações descritivas nas quais os representantes compartilhavam diversas características dos Ingarikó, por serem indígenas, embora não pudessem simbolizar a totalidade da cultura Ingarikó. Assim, os pontos de vista dos representantes giravam em torno da sua própria cultura, não chegando a abarcar as necessidades mais específicas dos Ingarikó.

Aos poucos, o povo Ingarikó começou a perceber uma disparidade entre a visibilidade dos interesses dos demais grupos e as suas próprias demandas. As políticas públicas voltadas às áreas da saúde e educação pareciam priorizar outros povos, deixando-os em segundo plano. Ao analisar essa disparidade, Faleiro (2015) admitiu a existência de esforços para diminuir os Ingarikó perante outras etnias. Não raro, o mínimo destaque aos interesses do povo da região da Serra do Sol costumava ser justificado pelo reduzido contingente populacional. 
Havia também a representação de pesquisadores e outros apoiadores do povo Ingarikó. Esses praticavam uma representação de interesses, defendendo as demandas dos indígenas mesmo sem compartilhar qualquer característica dos Ingarikó. Embora agradecidos pelo apoio recebido nos dois casos de representação, esses autóctones consideraram essas representações insuficientes, pois a criação do PNMR sinalizava a completa invisibilidade da sua territorialidade naquela área.

Em discussões internas, avaliaram a necessidade de se tornarem protagonistas da sua própria representação. Assim, os indígenas passaram a esboçar uma forma ampla de representação simbólica, praticada pela totalidade do seu povo. Diante da inviabilidade da participação de grande número de representantes nos diversos eventos de interesse, pensaram na possibilidade de atrair os representantes do poder público ao seu território.

A partir do ano 2000 os encontros que realizava apenas esporadicamente passaram a ocorrer com regularidade anual. Na V Assembleia Geral do Povo Ingarikó, realizada no ano de 2003, decidiram criar uma associação própria para facilitar as articulações com representantes do poder público. Como desdobramento dessa proposta, Falcão (2016) menciona a criação do Conselho do Povo Ingarikó (COPING). No mesmo evento foi definida a sede do COPING na cidade de Boa Vista/RR e a incumbência do conselho de organizar as assembleias gerais.

Desde as primeiras reuniões, as assembleias gerais assumiram um formato bastante democrático, com a participação dos indígenas na língua materna. Intercaladas com manifestações da espiritualidade, as discussões costumam se prolongar até o estabelecimento de consenso. Em relação ao parque nacional, as assembleias gerais se tornaram o principal canal de diálogos entre o povo Ingarikó e o órgão gestor do PNMR.

\section{NEGociaÇÃo COM O ÓRGÃo AmBIENTAL}

Uma das primeiras realizações do COPING foi a organização da VI Assembleia Geral do Povo Ingarikó realizada na comunidade Manalai em 2004, com a participação de diversas instituições públicas. Mesmo comportando discussões de todas as áreas de interesse dos indígenas, houve tempo para tratar do caso do parque nacional.

Diante de questionamentos sobre as possíveis interferências do parque nacional no modo de vida dos indígenas, as respostas do representante do órgão ambiental foram bastante apaziguadoras, pois o servidor público já considerava a possibilidade de criação de uma sobreposição oficial com o PNMR a partir da homologação da Terra Indígena Raposa Serra do Sol (TIRSS). Conforme Brasil (2000), o próprio plano de manejo interpretava a homologação da TIRSS como uma ameaça à unidade de conservação.

Ao término do evento, a ideia da sobreposição continuava suscitando questionamentos entre 0 povo Ingarikó. Por conta disso, o tema da superposição foi escolhido como principal assunto a ser discutido no encontro seguinte. Para alcançar maiores esclarecimentos, pensaram na confrontação entre representantes do poder público, estratégia possibilitada pelo envio de convites a diversas instituições.

Mlynarz (2006) menciona os convites estendidos ao Instituto Brasileiro do Meio Ambiente e dos Recursos Naturais Renováveis (IBAMA), FUNAI, Fundação Nacional de Saúde (FUNASA) e Ministério do Meio Ambiente (MMA), além do CIR e da Sociedade de Defesa dos Índios Unidos de Roraima (SODIURR). As discussões com início agendado para o dia 18 de abril de 2005 se tornaram ainda mais relevantes em razão da homologação da TIRSS, efetivada pelo Decreto s/nº 15 de abril de 2005, três dias antes do início da VII Assembleia Geral do Povo Ingarikó.

Segundo Brasil (2005), o decreto de homologação da TIRSS determinou a administração conjunta do PNMR, envolvendo a FUNAI, o IBAMA e o povo Ingarikó. O decreto também determinou a criação de um grupo de trabalho interministerial para a elaboração de um plano de administração conjunta.

O reconhecimento oficial da dupla afetação partiu da intenção do poder público de acomodar interesses e ao mesmo tempo utilizar o caso concreto como laboratório para a proposição de diretrizes para as demais situações de sobreposição. Assim, procurou abrigar demandas indígenas, estratégias de defesa nacional, proteção da biodiversidade e ainda avançar no 
cumprimento de determinações como as do artigo 57 da Lei no 9.985, de 18 de julho de 2000, que institui o Sistema Nacional de Unidades de Conservação da Natureza (SNUC).

As demandas dos povos originários por uma terra indígena que tivesse as dimensões territoriais condizentes com os territórios dos povos Macuxi, Taurepang, Wapixana, Patamona e Ingarikó eram bem conhecidas do poder público. Conforme Santilli (2001) a luta desses povos remontava às possibilidades oferecidas pela Lei do Amazonas № 941, de 16 de outubro de 1917, que havia viabilizado a delimitação de uma área para o usufruto dos índios Macuxi e Jaricuna no ano de 1919.

Após um período de sessenta anos de estagnação, as propostas de demarcações feitas nos anos de 1979, 1984 e 1993 haviam provocado uma série de desentendimentos por não contemplarem a totalidade dos territórios dos povos mencionados. Nessas condições, o poder público se viu impelido a contemplar a área proposta no estudo antropológico, mas sem abrir mão do parque nacional.

Para não provocar o acirramento das tensões, os direitos oferecidos aos indígenas foram acompanhados de algum empoderamento, pois a sobreposição reunia duas partes com cotas muito desiguais de poder. Uma maneira de transferir algum poder ao povo Ingarikó seria pela obrigatoriedade das negociações entre o poder público e os indígenas, possibilitadas pela divisão da responsabilidade de administração do parque nacional. Esse empoderamento colocou os indígenas numa posição privilegiada de negociação, permitindo o exercício da autonomia nos moldes propostos por Pulido (2006), como um tipo de liberdade democrática na qual a vontade se torna capaz de se autodeterminar.

O primeiro exercício de negociação entre o IBAMA, a FUNAI e o povo Ingarikó para a construção do plano de administração conjunta do PNMR se desenvolveu na III Assembleia Geral Extraordinária do Povo Ingarikó, realizada em agosto de 2005. Segundo Mlynarz (2006), logo no discurso de abertura o presidente do COPING expressou sua preocupação em entender como o PNMR iria preservar a área sem alterar o modo de vida indígena. Em outras palavras, o líder desejava saber como uma unidade de conservação de proteção integral poderia abrigar o uso sustentável em toda a sua extensão.

Conforme Mlynarz (2006), o representante do órgão ambiental respondeu que todas as ações institucionais respeitariam a vontade do povo Ingarikó. No momento seguinte, o representante da FUNAI foi ainda mais longe ao destacar que todas as ações concernentes à gestão do PNMR dependeriam do consentimento dos indígenas. No caso da construção do plano, todas as iniciativas partiriam dos Ingarikó, cabendo aos órgãos ambiental e indigenista o papel de mediação. As respostas dos representantes institucionais foram interpretadas pelos indígenas como uma situação especial na qual a proteção integral ocorreria somente nas áreas definidas pelos autóctones, em função dos pressupostos de sua cultura sobre o uso do território.

Confiando nas declarações dos representantes institucionais, os indígenas assumiram o protagonismo na elaboração do plano de gestão conjunta, contando com a participação dos órgãos ambiental e indigenista. Aproveitando a oportunidade e o apoio institucional, decidiram incorporar ao documento norteador da gestão do PNMR o seu próprio plano de vida. Cada parágrafo do plano foi pensado para possibilitar o atrelamento da gestão do parque nacional com o cotidiano da vida indígena e com as suas perspectivas de futuro.

Torna-se necessário lembrar que as negociações entre o povo Ingarikó e os órgãos ambiental e indigenista aconteceram num contexto de luta entre os povos da TIRSS e diversos fazendeiros, garimpeiros, o governo de Roraima e outros setores da sociedade roraimense. Além dos conflitos envolvendo tentativas de homicídio de indígenas, protagonizados por fazendeiros, o governo do estado decidiu ampliar suas estratégias de ataque ao decreto de homologação entrando com uma ação do STF para solicitar a exclusão da parte da TIRSS que se encontrava sobreposta ao PNMR. Conforme Brasil (2009), essa ação imposta no ano de 2008 se somou a outras solicitações no âmbito da Petição no 3.388 .

Mesmo em meio aos conflitos, o plano de gestão conjunta foi concluído no ano de 2008. Após a sua apreciação pelos envolvidos, o documento foi enviado para a análise da FUNAl e do Instituto Chico Mendes de Conservação da Biodiversidade (ICMBio), órgão ambiental criado pela Lei $n^{\circ}$ 11.516, de 28 de agosto de 2007, para administrar todas as unidades de 
conservação federais do país. Todavia, o documento esbarrou nos micropoderes dos servidores públicos.

Para Faleiro (2015), os servidores contrários ao plano de gestão já haviam utilizado seus micropoderes para atrasar a criação do grupo de trabalho interinstitucional, publicado somente no ano de 2008. Na fase de análise do plano de gestão, os micropoderes foram usados para atrasar a sua tramitação pelos diversos departamentos. Interessante notar que a mesma estratégia de protelação aconteceu tanto na FUNAI quanto no ICMBio.

Enquanto o plano de administração conjunta era apreciado pelos órgãos mencionados, o STF iniciou a análise da Petição no 3.388, relativa à TIRSS. Como o julgamento envolvia o PNMR, os servidores contrários ao plano de gestão puderam justificar o atraso nos trâmites pela necessidade de aguardar a decisão do STF. Segundo Rodrigues e Ferreira (2013), o julgamento concluído no ano de 2009 impôs dezenove condicionantes à TIRSS, incluindo a condição de reconhecer o órgão ambiental como único gestor do PNMR. Essa determinação deixou muitos dos contrários ao plano motivados para acelerar as tramitações.

Conforme Brasil (2010), baseando-se nas condicionantes do STF os pareceres variaram desde o apelo para não se falar mais em gestão conjunta até indicações mais apaziguadoras mencionando a possibilidade de aproveitamento do seu conteúdo na revisão do plano de manejo do PNMR. Ao final das análises, o plano de gestão conjunta foi rejeitado pelo ICMBio.

No mesmo período, Silveira (2010) refletiu sobre a decisão do STF de desfazer a gestão tripartite do parque nacional. Para o autor, as constituições mais recentes têm incorporado uma grande quantidade de novos direitos sem a preocupação com a sua materialização, dando a impressão que são criados para não serem cumpridos. Essa prática faz lembrar as considerações de Pinto (2011) sobre a facilidade de distribuição de direitos, em razão da sua soma variável.

Silveira (2010) também destaca que a sobreposição envolve os direitos fundamentais difusos do ambiente e os direitos igualmente fundamentais, porém coletivos, dos indígenas. Ambos os direitos possuem núcleos essenciais que segundo o ordenamento jurídico brasileiro não podem ser afetados, sob pena de um dos direitos se tornar inexistente no âmbito da superposição. Dependendo da análise do caso concreto, a proteção dos núcleos dos direitos essenciais em sopesamento pode exigir a prevalência pouco comum dos direitos coletivos sobre os difusos.

Para Silveira (2010), tanto no núcleo do direito difuso quanto no correspondente do direito coletivo se encontra a proteção da vida. No primeiro caso, a vida diz respeito a todos os seres humanos. No segundo caso, se restringe à vida dos indígenas. Para estabelecer a prevalência de um dos direitos, caberiam duas perguntas e suas respectivas respostas: Se não existisse o PNMR, a vida de todos os brasileiros estaria em risco? Certamente que não. E, se não existisse o território Ingarikó, estaria em risco a vida desses indígenas? Os exemplos do passado indicam que sim. Nesse caso, as normas do artigo 231 da Constituição Federal realizam mais diretamente os direitos fundamentais dos indígenas e por isso prevalecem sobre as normas do artigo 225 da Carta Magna.

Com um entendimento diferente, o STF decidiu que o direito difuso do ambiente prevaleceria sobre o direito coletivo dos indígenas. Em suas argumentações, também vislumbrou uma perfeita compatibilidade entre a preservação e o usufruto indígena. Essa conclusão parece não ter levado em conta o sentido histórico do termo preservação, pois a palavra sempre esteve ligada à estratégia de proteção integral. Para Santilli (2004), não há dúvida que a preservação requeira a intocabilidade de determinadas áreas.

Talvez a pergunta do líder Ingarikó sobre a possibilidade de uso sustentável em toda a extensão de uma unidade de conservação de proteção integral pudesse ser lançada à Suprema Corte, para que pudessem finalmente dar a resposta buscada por tanto tempo. Diante dessa situação, o povo Ingarikó passou a apostar na continuidade da estratégia de resistência. 


\section{ESTRATÉGIA DE RESISTÊNCIA DO POVO INGARIKÓ}

A estratégia de resistência às regras do parque nacional se iniciou com as primeiras notícias da existência de uma unidade de conservação de proteção integral em seu território. As tensões diminuíram um pouco quando os representantes do órgão ambiental passaram a garantir que 0 modo de vida indígena seria respeitado. Alguns anos depois, a publicação do decreto de homologação que determinava a gestão conjunta tornou-se determinante para apaziguar as tensões, transformando os conflitos manifestos em latentes. Para aceitar a existência do PNMR e participar da elaboração de um plano de gestão, os Ingarikó colocaram a condição de se tornarem os protagonistas da construção do plano.

A opção pelo protagonismo guarda relações com o que Howard (2002) menciona sobre a cultura dos povos da família linguística Proto-Caribe. Mesmo antes da chegada dos europeus, alguns desses povos mantinham o costume de metamorfosear e domesticar os bens de troca. Quando conseguiam captar as propriedades dos produtos oriundos de outros povos para satisfazer suas próprias finalidades, acreditavam estar se apropriando e pacificando os poderes de outros grupos.

Para Howard (2002), esse comportamento também foi adotado nas relações com os europeus. A transformação e domesticação dos produtos simbolizava a desconstrução do capital simbólico do colonizador e sua reconstrução à imagem da sociedade indígena. Essa visão alcançou os dias atuais como uma forma sutil e eficaz de resistência cotidiana, voltada ao estabelecimento de relações com os brancos sem se deixar dominar por eles.

No caso dos Ingarikó, Amaral (2014) afirma que sua abertura ao exterior está sempre condicionada a um tipo de apropriação caracterizada pela domesticação. Assim, o anseio pela liderança na elaboração do plano correspondeu ao desejo de desconstrução do capital simbólico representado pelo parque nacional e sua reconstrução à imagem do povo Ingarikó. No que dependesse dos indígenas, a metamorfose do PNMR abrangeria até mesmo o nome da unidade de conservação. Para Fukuda (2009), um líder Ingarikó revelou a intenção de acrescentar o termo indígena ao nome do PNMR, que passaria a se chamar Parque Nacional Indígena do Monte Roraima.

Segundo Brasil (2008), uma das seções do plano de gestão conjunta, dedicada às ações emergenciais, foi denominada pelo povo Ingarikó de Pata Eseru. De acordo com as informações levantadas em campo, o termo significa do nosso jeito ou do jeito da nossa cultura. O termo empregado expressa a intenção dos Ingarikó de domesticar ou indianizar o parque nacional.

Com a determinação imposta pelo STF para tornar o órgão ambiental o único responsável pela gestão do PNMR, a obrigatoriedade da negociação com os indígenas deixou de existir. Essa medida retirou o empoderamento indígena anteriormente concedido. Porém, os indígenas continuaram resistindo por acreditarem em outro poder, aquele proveniente da territorialidade Ingarikó. Eles sabiam que o órgão ambiental não tinha condições de fazer a gestão de forma unilateral. A localização geográfica, as dificuldades de acesso e os custos diários de permanência no parque nacional tornam a gestão inviável sem o apoio dos indígenas. Essa realidade confere um poder mais concreto aos indígenas.

Enquanto isso, a análise do conjunto das situações de sobreposição levou o poder executivo a publicar o Decreto no 7.747, de 5 de junho de 2012, que instituiu a Política Nacional de Gestão Territorial e Ambiental de Terras Indígenas (PNGATI). Conforme Brasil (2012), a norma determinou a elaboração e implementação de planos conjuntos de gestão, reconhecendo a necessidade de acordos entre as partes envolvidas nos casos de dupla afetação.

O texto do decreto procurou acatar a determinação do STF ao deslocar um dos termos que dariam nome aos documentos produzidos. Segundo Brasil (2012), ao invés de plano de gestão conjunta a norma passou a exigir um plano conjunto de gestão, mudando o sentido da expressão. Por outro lado, determinou a elaboração e execução conjuntas, obrigando o órgão ambiental a negociar com as demais partes envolvidas a gestão das unidades de conservação em situação de superposição. 
Embora a PNGATI não tenha devolvido a divisão da responsabilidade pela gestão, restaurou a necessidade de negociação, trazendo de volta o empoderamento anteriormente concedido ao povo Ingarikó. Essa nova situação também recuperou a possibilidade de exercício da autonomia indígena nos diálogos com o órgão ambiental, facilitando a continuidade da estratégia sutil e eficaz de resistência indígena.

\section{CONSIDERAÇÕES FINAIS}

Sem saber das reais intenções do poder público, os Ingarikó concluíram que a criação da unidade de conservação em seu território havia ocorrido em função da sua invisibilidade perante o poder público. Para fazer frente a essa iniciativa estatal, iniciaram uma luta por reconhecimento e redistribuição apoiada em estratégias de representação, negociação e resistência.

Ao invés de continuar permitindo serem representados por outros povos e organizações indígenas, decidiram assumir o protagonismo da sua própria representação. Por meio da organização de eventos conhecidos como assembleias gerais puderam expor suas demandas diretamente aos representantes do poder público.

Nas assembleias gerais também colocaram em prática a estratégia de negociação, que incluiu o caso do parque nacional. Partindo de uma posição de contrariedade à existência da unidade de conservação, acabaram aceitando a existência da unidade de conservação mediante as determinações do decreto de homologação da TIRSS e a garantia dos representantes do órgão ambiental sobre o respeito ao modo de vida indígena na área sobreposta.

Porém, quando o empoderamento concedido foi retirado pelo STF, os Ingarikó se firmaram ainda mais na estratégia de resistência. Sabedores da inviabilidade de um processo de administração conduzido unicamente pelo poder público, seguiram promovendo a gestão do parque nacional segundo os pressupostos da sua própria territorialidade.

Alguns anos depois, a preocupação do poder executivo com a impossibilidade de executar a gestão das áreas duplamente afetadas de forma unilateral suscitou a publicação do decreto da PNGATI, que restituiu a obrigatoriedade de negociação com os povos locais. A nova norma restaurou o empoderamento dos Ingarikó, além de possibilitar o exercício da autonomia indígena nas negociações com o órgão ambiental. Assim, a resistência indígena passou a condicionar a gestão da área sobreposta à visibilidade da sua territorialidade e suas expectativas para o futuro.

\section{REFERÊNCIAS}

$A B I-E C ̧ A B$, Pedro. Presença indígena em unidades de conservação. 2008. 159 p. Dissertação (Mestrado em Direito das Relações Internacionais) - Pontifícia Universidade Católica de São Paulo, São Paulo, 2008.

ABREU, Maria Aparecida (Org.). Redistribuição, reconhecimento e representação: diálogos sobre igualdade de gênero. Brasília: IPEA, 2011. 222 p.

AMARAL, Maria Virginia Ramos. A caminho do mundo-luz celestial: o Areruya e os profetismos Kapon e Pemon. 2014. Dissertação (Mestrado em Antropologia Social) - Museu Nacional, Universidade Federal do Rio de Janeiro, Rio de Janeiro, 2014.

ARAÚJO, Clara; BIROLI, Flávia. Mulheres, mídia e política. In: ABREU, Maria Aparecida (Org.). Redistribuição, reconhecimento e representação: diálogos sobre igualdade de gênero. Brasília: IPEA, 2011. 222 p.

ARAUJO, Fabiola Souza; RESENDE, Ana Catarina Zema. Pensão por morte e poligamia indígena: redistribuição ou reconhecimento? In: ENCONTRO NACIONAL DO CONPEDI - UFS, 24, 2015, Florianópolis. Anais... Florianópolis: CONPEDI, 2015. p. 436-452.

ARRUDA, Rinaldo. "Populações tradicionais" e a proteção dos recursos naturais em unidades de conservação. Revista Ambiente e Sociedade. São Paulo, n. 5, p. 79-92, 1999. https://doi.org/10.1590/S1414-753X1999000200007 
BRASIL. Decreto no 97.887, de 28 de junho de 1989. Cria o Parque Nacional do Monte Roraima e dá outras providências. Diário Oficial da República Federativa do Brasil, Brasília, DF, 29 jun. 1989.

BRASIL. Lei o 9.985 , de 18 de julho de 2000. Institui o Sistema Nacional de Unidades de Conservação da Natureza e dá outras providências. Diário Oficial da República Federativa do Brasil, Brasília, DF, 19 ago. 2000.

BRASIL. Ministério do Meio Ambiente. Instituto Chico Mendes de Conservação da Biodiversidade. SOS Monte Roraima: Informações Gerais e Institucionais. Brasília: IBAMA, 2004. $91 \mathrm{p}$.

BRASIL. Decreto s/n. de 15 de abril de 2005. Homologa a demarcação administrativa da Terra Indígena Raposa Serra do Sol, localizada nos municípios de Normandia, Pacaraima e Uiramutã, no Estado de Roraima. Diário Oficial da União, Brasília, DF, 18 abr. 2005.

BRASIL. Ministério do Meio Ambiente. Instituto Chico Mendes de Conservação da Biodiversidade. Plano de Administração da Área sob Dupla Afetação pelo Parque Nacional Monte Roraima e a Terra Indígena Raposa Serra do Sol - Plano Pata Eseru. ICMBio: Brasília, 2008. 54 p.

BRASIL. Supremo Tribunal Federal. Ação Popular. Demarcação da Terra Indígena Raposa Serra do Sol. Embargo Declaratório na Petição no 3.388 Roraima. Augusto A. B. Neto, Cláudio V. N. Quadros, Francisco M. M. Cavalcanti, Antonio G. de Morais e outros, União. Relator Ministro Carlos Britto. Acórdão. Brasília: STF, 2009.

BRASIL. Ministério do Meio Ambiente. Processo no 02001-003855/2006-10. Brasília, p. 290295, 2010. Documento não publicado.

BRASIL. Decreto oㅜ 7.747, de 5 de junho de 2012. Institui a Política Nacional de Gestão Territorial e Ambiental de Terras Indígenas - PNGATI, e dá outras providências. Diário Oficial da República Federativa do Brasil, Brasília, DF, 6 jun. 2012.

BRASIL. Ministério da Saúde. Secretaria Especial de Saúde Indígena. Distrito Sanitário Especial Indígena do Leste de Roraima. Censo Populacional. Boa Vista: DSEI Leste Roraima, 2017.

BURIL, Bárbara. Reflexões sobre o diagnóstico da invisibilidade na teoria de Axel Honneth. 2017. Disponível em: <https://blogdosociofilo.wordpress.com>. Acesso em 13 jan. 2018.

CARLEHEDEN, Mikael; HEIDEGREN, Carl-Göran; WILLIG, Rasmus. Recognition, social invisibility and disrespect. Journal of Social Theory, v. 13, n. 1, p. 1-3, abr. 2012. https://doi.org/10.1080/1600910X.2012.648734

CARVALHO, Priscila. Conflitos sociais, moralidade e justiça. Ethica, Florianópolis, v. 14, n. 1, p. 13-35, jul. 2015. https://doi.org/10.5007/1677-2954.2015v14n1p13

CITTADINO, Gisele. Igualdade e "invisibilidade". Ciência Hoje, Rio de Janeiro, v. 37, p. 28-33. 2005.

CRUZ, Maria Odileiz Sousa. Fonologia e Gramática Ingarikó. Amsterdam: Vrije Universiteit Amsterdam, 2005. 464 p.

CYFER, Ingrid; NEVES, Raphael. Entrevista com Nancy Fraser. In: ABREU, Maria Aparecida (Org.). Redistribuição, reconhecimento e representação: diálogos sobre igualdade de gênero. Brasília: IPEA, 2011. 222 p.

DERANTI, Jean-Philippe; RENAULT, Emmanuel. Politicizing Honneth's ethics of recognition. London: Sage Publications, 2007. 20 p.

FALCÃO, Márcia Teixeira. Ambiente e conhecimento tradicional da etnia Ingarikó na terra indígena Raposa Serra do Sol - Roraima: abordagem etnocientífica no estudo do uso da terra. Belém: BIONORTE, 2016. 106 p. Tese (Doutorado em Biodiversidade e Conservação) Programa de Pós-Graduação em Biodiversidade e Biotecnologia da Rede BIONORTE, Museu Paraense Emílio Goeldi e Universidade Federal do Pará. 
FALEIRO, Rodrigo Paranhos. Alegorias das políticas de territorialidade: uma análise comparada da sobreposição do Parque Nacional do Monte Roraima e a Terra Indígena Raposa Serra do Sol em terras Ingarikó. Brasília: UnB, 2015. 188 p. Tese (Doutorado em Ciências Sociais) - Centro de Pesquisa e Pós-Graduação sobre as Américas, Universidade de Brasília. 2015.

FARAGE, Nádia; SANTILLI, Paulo. TI/Raposa Serra do Sol: fundamentos históricos. São Paulo: Instituto Socioambiental, 2018. Disponível em: <https://util.socioambiental.org>. Acesso em: 28 jun. 2018.

FIOROTTI, Devair Antônio. Erenkon do Circum-Roraima: ou uma poética da repetição. 0 Eixo e a Roda, Belo Horizonte, v. 26, n. 3, p. 101-128, 2017. https://doi.org/10.17851/23589787.26.3.101-128

FRANK, Erwin Heinrich. Os Macuxi são mesmo "do Caribe"? Revista NUHSA, Boa Vista, v. 1, n. 2, p. 11-36, out. 2008.

FRASER, Nancy. Reconhecimento sem ética. São Paulo: Lua Nova, 2007. https://doi.org/10.1590/S0102-64452007000100006

FUKUDA, Juliana Cristina. Sobreposição de unidades de conservação e terras indígenas: o caso da área do Parque Nacional do Monte Roraima e a TI Raposa Serra do Sol. 2009. 31 p. Monografia (Especialização em Indigenismo e Desenvolvimento Sustentável) - Centro de Desenvolvimento Sustentável - Universidade de Brasília. 2009.

FUNDAÇÃO ECOAMAZÔNIA. Evolução da população Ingarikó no norte e nordeste de Roraima. Boa Vista: Ecoamazônia, 2018. Disponível em: <www.ecoamazonia.org.br>. Acesso em 15 ago. 2018.

HIRATA, Helena. O trabalho do cuidado (care) em perspectiva comparada: França, Japão e Brasil. In: ABREU, Maria Aparecida (Org.). Redistribuição, reconhecimento e representação: diálogos sobre igualdade de gênero. Brasília: IPEA, 2011. 222 p.

HONNETH, Axel. Luta por reconhecimento: a gramática moral dos conflitos sociais. Trad. Luiz Repa. São Paulo: Editora 34, 2003. 291 p.

HONNETH, Axel; MARGALIT, Avishai. Invisibility: on the epistemology of recognition. Aristotelian Society, n. 1, v. 75, p. 111-126, jul. 2015. https://doi.org/10.1111/1467-8349.00081

HOWARD, Catherine V. A domesticação das mercadorias: estratégias Waiwai. In: ALBERT, Bruce; RAMOS, Alcida Rita. (Org.). Pacificando o branco: cosmologias do contato no Norteamazônico. São Paulo: UNESP, 2002. https://doi.org/10.4000/books.irdeditions.24722

INGARICÓ, Larangera Maurício Sales. Wekuik: o calendário cultural do povo Ingarikó. Boa Vista: UFRR, 2012. 70 p. Trabalho de Conclusão de Curso (Graduação) - Curso de Licenciatura Intercultural, Universidade Federal de Roraima, Boa Vista, 2012.

LAURIOLA, Vincenzo M. De quem é o Monte Roraima? Terras indígenas e unidades de conservação entre os dilemas da conservação na Amazônia brasileira. Passages de Paris, p. 53-110, 2011.

LUQUIARI, Paluana Curvelo. Movimentos sociais. São Bernardo do Campo: Colégio Singular, 2018. Disponível em: <www.singularsaobernardo.com.br>. Acesso em: 05 fev. 2018.

MERIGUETI, Diego Souza. Da invisibilidade ao reconhecimento: o processo como instrumento de luta dos refugiados pela efetividade de seus direitos. 2017. 188 p. Dissertação (Mestrado em Direito) - Programa de Pós-Graduação em Direito Processual, Universidade Federal do Espírito Santo, Vitória, 2017.

MLYNARZ, Ricardo Burg. Parque Nacional do Monte Roraima: constituindo a arena de negociação política dos Ingarikó frente à conservação da natureza, em terra indígena. In: Encontro da ANPPAS, 3, 2006, Brasília/DF. Anais... Brasília, ANPPAS, 2006. 14 p.

MORAES, Renato. Teoria do reconhecimento e movimentos sociais: o potencial de transformação de ações coletivas moralmente motivadas. Interações - Cultura e Comunidade, v. 1, n. 1, p. 66-80, 2006. 
MOUSQUER, Francis. Reconhecimento e invisibilidade. In: Congresso Estadual de Teologia, 2, 2015, São Leopoldo. Anais... São Leopoldo: URI, 2015.

PEREIRA, Ana Carolina. Redistribuição e reconhecimento: categorias integradas para um modelo de justiça social. Rio de Janeiro: PUC, 2013. 33 p.

PINTO, Céli. A derrota que se repete: as mulheres nas eleições para o legislativo em 2010. In: ABREU, Maria Aparecida (Org.). Redistribuição, reconhecimento e representação: diálogos sobre igualdade de gênero. Brasília: IPEA, 2011. 222 p.

PULIDO, C. B. O conceito de liberdade na teoria política de Norberto Bobbio. Tradução Julio Pinheiro Faro Homem de Siqueira. [S.I.]: Revista de Economía Institucional, 2006. 24 p.

RICARDO, Fany.; MACEDO, Valéria. Apresentação. In: RICARDO, Fany. (Org.). Terras indígenas e unidades de conservação da natureza: 0 desafio das sobreposições. São Paulo: Instituto Socioambiental, 2004. 690 p.

RODRIGUES, Priscilla Cardoso; FERREIRA, Rafael Reis. Sobreposição de unidades de conservação em terras indígenas no estado de Roraima. In: VITA, Jonathan Barros et al. Direitos fundamentais e democracia II. Florianópolis: FUNJAB, 2013.

RORAIMA. Secretaria de Desenvolvimento e Planejamento. Base cartográfica. Boa Vista: SEPLAN, 2018.

SANTILLI, Márcio. A cilada corporativa. In: RICARDO, Fany (Org.). Terras indígenas e unidades de conservação da natureza: o desafio das sobreposições. São Paulo: Instituto Socioambiental, 2004. 690 p.

SANTILLI, Paulo. Pemongon Patá: território Macuxi, rotas de conflito. São Paulo: UNESP, 2001. $227 \mathrm{p}$.

SCHMIDT, Paige; PETERSON, Markus. Biodiversity Conservation and Indigenous Land Management in the Era of Self-Determination. Consevation Biology, n. 6, v. 23, p. 1458-1466. 2009. https://doi.org/10.1111/j.1523-1739.2009.01262.x

SILVA, Cristina Faria.; SILVA, Helder Antônio. Direito de propriedade e proteção ambiental: estudo de caso das unidades de conservação da natureza no município de Barbacena - MG. Revista das Faculdades Integradas Vianna Júnior. Juiz de Fora, v. 5, n. 1, p. 112-147, jan./jun. 2014.

SILVA, Cristhian Teófilo. The astonishing resilience: ethnic and legal invisibility of indigenes from a brazilian perspective. Vibrant, Brasília, n. 2, v. 4, p. 97-119, 2007.

SILVEIRA, Edson Damas. Meio ambiente, terras indígenas e defesa nacional: direitos fundamentais em tensão nas fronteiras da Amazônia brasileira. Curitiba: Juruá, 2010. 312 p.

SIMIM, Tiago Aguiar. Invisibilidade social a partir do filme "O som ao redor": uma análise honnethiana das patologias sociais no Brasil. Ciências Sociais Unisinos, v. 51, n. 1, p. 52-60, jan./abr. 2015. https://doi.org/10.4013/csu.2015.51.1.06

TOMÁS, Júlia Catarina de Sá Pinto. A invisibilidade social: uma perspectiva fenomenológica. IV Congresso Português de Sociologia, Lisboa, jun. 2008.

WIESNER, Martha Luz Rojas; DEVARGAS, Maria. Strategic invisibility as everyday politics for a life with dignity: Guatemalan women migrants' experiences of insecurity at Mexico's Southern Border. Hexagon Series, v. 9, p. 193-211. 2013. https://doi.org/10.1007/978-3-642-28012-2 10

ZURN, Christopher. Axel Honneth. Cambridge: Polity, 2015. 257 p.

Recebido em: 15/08/2018

Aceito para publicação em: 21/11/2018

$\begin{array}{lllll}\text { Caminhos de Geografia } & \text { Uberlândia-MG } & \text { v. 20, n. } 70 & \text { Junho/2019 } & \text { p. 478-491 Página } 491\end{array}$

